The clinical evidence shows, therefore, that metronidazole is effective in non-specific vaginitis, but these results pose a difficult question: Does the drug achieve clinical success by virtue of its antianaerobic activity, by its (much less good) activity against $G$ vaginalis, or by both mechanisms ? Further possible evidence for the part played by anaerobes, particularly Bacteroides spp (but not $B$ fragilis) and peptococci in nonspecific vaginitis, has been produced by Spiegel et al, ${ }^{11}$ who suggest that non-specific vaginitis may be caused by anaerobes in conjunction with $G$ vaginalis. Such a hypothesis would be compatible with many other so-called anaerobic infections, notably those in the gastrointestinal tract, where mixed infections including aerobes are so common and pure anaerobic infection so rare. Not only is treatment of these mixed infections with metronidazole alone frequently very effective $^{1213}$ but prophylaxis with metronidazole alone also successfully prevents postoperative wound infection after elective colorectal surgery. ${ }^{14}$ The therapeutic success of metronidazole is more difficult to evaluate in non-specific vaginitis than in the mixed infections of the gastrointestinal tract, since it is active in vitro against both the aerobic and the anaerobic components of the infection in the vagina but only against the anaerobes in the gut. If it were possible to use a drug highly active against anaerobes but inactive against $G$ vaginalis their relative contributions to pathogenesis might become clear.

In practical terms, however, these studies suggest that nonspecific vaginitis is yet another infection which comes into the anaerobic category currently so fashionable; and they offer some cause for real optimism to those concerned with treatment of this recalcitrant condition. Nevertheless, this optimism should be tempered with caution: before metronidazole becomes widely used in an uncritical fashion some more carefully controlled studies are needed.

${ }^{1}$ Leopold S. Heretofore undescribed organism isolated from the genitourinary system. United States Armed Forces Medical fournal 1953;4: 263-6.

${ }^{2}$ Gardner HL, Dukes CD. Haemophilus vaginalis vaginitis. A newly defined specific infection previously classified "nonspecific" vaginitis. $A m \mathfrak{F}$ Obstet Gynecol 1955;69:962-76.

3 Zinnemann K, Turner GC. The taxonomic position of "Haemophilus vaginalis" (Corynebacterium vaginale). Fournal of Pathology and Bacteriology 1963;85:213-9.

4 Greenwood JR, Pickett MJ. Transfer of Haemophilus vaginalis Gardner and Dukes to a new genus, Gardnerella: G. vaginalis (Gardner and Dukes) comb nov. International fournal of Systematic Bacteriology $1980 ; 30: 170-8$

${ }^{5}$ Smith RF, Dunkelberg WE. Inhibition of Corynebacterium vaginale by metronidazole. Sex Transm Dis 1977;4:20-1.

${ }^{6}$ Ralph ED, Austin TW, Pattison FL, Schieven BC. Inhibition of Haemophilus vaginalis (Corynebacterium vaginale) by metronidazole, tetracycline and ampicillin. Sex Transm Dis 1979;6:199-202.

${ }^{7}$ Ralph ED, Amatnieks YE. Relative susceptibilities of Gardnerella vaginalis (Haemophilus vaginalis), Neisseria gonorrhoeae, and Bacteroides fragilis to metronidazole and its two major metabolites. Sex Transm Dis 1980;7: 157-60.

${ }^{8}$ Pheifer TA, Forsyth PS, Durfee MA, Pollock HM, Holmes KK. Nonspecific vaginitis. Role of Haemophilus vaginalis and treatment with metronidazole. N Engl f Med 1978;298:1429-34.

${ }^{9}$ Balsdon MJ, Taylor GE, Pead L, Maskell R. Corynebacterium vaginale and vaginitis: a controlled trial of treatment. Lancet $1980 ; \mathrm{i}: 501-3,4$.

${ }^{10}$ Malouf M, Fortier M, Moran G, Dube J-L. Treatment of Haemophilus vaginalis vaginitis. Obstet Gynecol 1981;57:711-4.

11 Spiegel CA, Amsel R, Eschenbach D, Schoenknecht F, Holmes KK. Anaerobic bacteria in nonspecific vaginitis. $N$ Engl f Med $1980 ; 303$ : 601-7.

12 Eykyn SJ, Phillips I. Metronidazole in surgical infections. $\mathcal{F}$ Antimicrob Chemother 1978;4, suppl C:75-81.

13 Willis AT, Ferguson IR, Jones PH, et al. Metronidazole in prevention and treatment of bacteroides infections in elective colonic surgery. Br Med $\mathcal{f}$ 1977;i :607-10.

14 Eykyn SJ, Jackson BT, Lockhart-Mummery HE, Phillips I. Prophylactic peroperative intravenous metronidazole in elective colorectal surgery. Lancet 1979 ;ii:761-4.

\section{How does acupuncture work?}

Acupuncture is a potentially cheap and safe form of treatment for relieving some types of pain, yet many doctors in the West remain sceptical of its value. They find the ancient Chinese concepts of traditional acupuncture and its claim to be a treatment for all ills unacceptable, but these concepts may be largely irrelevant to the practice of effective analgesic acupuncture. Sceptics suggest that acupuncture may be nothing more than a powerful placebo. If, however, acupuncture exerts some specific analgesic effect like other physical treatments, this is not amenable to proof by formal clinical trial. Acupuncture may be performed in several ways, including manual rotation of the needles and low-frequency or high-frequency electrical stimulation through them. No truly double-blind comparison can be made with alternative treatments since the needles must be inserted in the conscious patient. Despite the scepticism, however, evidence is accumulating about its mechanisms of action.

The possibility that acupuncture analgesia is mediated by a humoral factor was first suggested by a report that transfer of cerebrospinal fluid from rabbits having acupuncture produces analgesia in recipient rabbits. ${ }^{1}$ The time course of analgesia is similar whether induced by acupuncture or by stimulation of the brainstem periaqueductal grey matter, both forms of stimulation producing effects with a delayed beginning and end. ${ }^{2}$ Analgesia induced by stimulating neurones of the periaqueductal grey matter appears to be mediated by endogenous opiate-like peptides, ${ }^{3}$ so perhaps analgesia after acupuncture is produced by the release of similar endogenous substances.

The endogenous peptides with opiate-like analgesic effects are broadly classed as enkephalins and endorphins. Research into the role of these opioids in acupuncture analgesia falls into into two main categories: firstly, the use of drugs modifying opiate action and, secondly, the measurement of opioid peptide concentrations in blood and cerebrospinal fluid. The specific opiate-receptor-blocking drug naloxone reduces or abolishes low-frequency $(2-6 \mathrm{~Hz})$ electroacupuncture analgesia in various animals subjected to pain..$^{4-7}$ Naloxone has no effect, however, on the analgesia induced by high-frequency $(200 \mathrm{~Hz})$ electroacupuncture in mice. ${ }^{4}$ The degree of analgesia in these studies was assessed by behavioural measurements, ${ }^{45}$ by the depression of the firing rate of pain-transmitting (nociceptive) spinal neurones, ${ }^{6}$ or by changes in pain-induced cortical evoked potentials. ${ }^{7}$ In human subjects with chronic or experimental pain all but one group of workers report that naloxone reduces the analgesia produced by manual acupuncture or low-frequency electroacupuncture via needles or surface electrodes. ${ }^{28-10}$

Certain D-amino-acids inhibit the peptidases that otherwise rapidly degrade the endorphins, thus limiting the duration of their effects. These D-amino-acids enhance the effect of lowfrequency electroacupuncture in mice, the resulting analgesia being reversible by naloxone. ${ }^{11}$ Mice of the inbred strain CXBK have a low density of opiate receptors in the brain and achieve little analgesia after morphine or acupuncture. ${ }^{12}$ In contrast, the related group of C57BL mice, which have a normal density of brain opiate receptors, respond to acupuncture and morphine with normal analgesia. This evidence further supports a role for endogenous opioid peptides in acupuncture analgesia.

Some recent evidence points to the release of opioid pep- 
tides in cerebrospinal fluid during acupuncture analgesia. Several workers have shown an increase in opiate-like activity in the cerebrospinal fluid of animals and man during acupuncture, ${ }^{13-15}$ but this was measured by a radioreceptor assay that lacked specificity and did not identify structurally discrete peptides. Clement-Jones et al $^{16-18}$ measured cerebrospinal concentrations of beta-endorphin and met-enkephalin by radioimmunoassay in two groups of patients before and after 30 minutes of electroacupuncture. They used a highly specific met-enkephalin assay that had insignificant crossreaction with other peptides. ${ }^{16} \mathrm{~A}$ group of patients with recurrent pain received low-frequency electroacupuncture. Concentrations of met-enkephalin in the cerebrospinal fluid were unchanged but those of beta-endorphin rose after electroacupuncture. ${ }^{17}$ In a second study, in heroin addicts who were being withdrawn from their drugs, high-frequency electroacupuncture was given to suppress the symptoms and signs of withdrawal. Clinically the treatment was highly effective and it was associated with a rise in met-enkephalin concentrations, which had been low before treatment; beta-endorphin concentrations, which were raised initially, did not change after electroacupuncture. ${ }^{18}$ The difference between the effects on beta-endorphin and met-enkephalin may be due to the different conditions being treated, but more probably relate simply to the frequencies of the stimuli. Thus low-frequency electroacupuncture releases beta-endorphin, whose effects can be blocked, at least in part, by naloxone; whereas highfrequency electroacupuncture may release met-enkephalin, whose effects are not blocked by conventional doses of naloxone.

Information about changes in opioids in blood during acupuncture is more confused. The results of two studies suggest that circulating immunoreactive beta-endorphin rises during electroacupuncture, ${ }^{1920}$ but stress was not excluded as a cause of the changes. Beta-endorphin is released from the pituitary in parallel with adrenocorticotrophic hormone and the lipotrophins during stress and indeed all other known stimuli. Other workers have reported a fall in plasma adrenocorticotrophic hormone as well as beta-endorphin and cortisol concentrations during electroacupuncture, ${ }^{18}{ }^{21}$ an effect compatible with the central release of enkephalins. ${ }^{22}{ }^{23}$ In any event, beta-endorphin released into the blood is unlikely to mediate the central analgesia induced by acupuncture, since this peptide penetrates poorly into the central nervous system. Pomeranz et al found that hypophysectomy blunted the analgesic response to low-frequency electroacupuncture, ${ }^{24}$ but this has not been confirmed. ${ }^{5}$ In man the pituitary is probably not an important source of cerebral beta-endorphin, since the concentrations in the cerebrospinal fluid are normal in patients with panhypopituitarism, who have undetectable plasma concentrations of beta-endorphin. ${ }^{2.5}$

5-Hydroxytryptamine (serotonin) probably plays an important part in mediating the analgesic effect of acupuncture. ${ }^{26-28}$ The tryptophan hydroxylase inhibitor parachlorphenylalanine decreases concentrations in the brain of 5-hydroxytryptamine but works in the opposite way to naloxone, reducing the analgesic effect of high-frequency electroacupuncture in mice but having no effect on lowfrequency electroacupuncture analgesia. ${ }^{4}$ Other neurotransmitter systems may mediate some effects of acupuncture but so far their role is uncertain. ${ }^{28}{ }^{29}$

The effects of low-frequency electroacupuncture and manual acupuncture may be mediated, at least in part, by stimulation of beta-endorphin-containing neurones of the periaqueductal grey matter, thereby activating endogenous pain- control pathways. An important 5-hydroxytryptamine-containing pathway that inhibits pain arises in the nucleus raphe magnus in the medulla and projects to the spinal dorsal horns. Stimulation of this serotoninergic system activates inhibitory enkephalinergic interneurones situated in the spinal dorsal horns, which in turn inhibit the activity of nociceptive neurones in the dorsal horns. ${ }^{30}$ Possibly high-frequency electroacupuncture has an effect in activating this serotoninergic-enkephalinergic system.

Can we now assert that acupuncture is more than a placebo? This question seems no longer relevant, since the relief of pain associated with placebos is probably also mediated by release of endogenous opioids and can be blocked by naloxone. ${ }^{31}$ Perhaps the evidence that different forms of acupuncture elicit specific neurohumoral effects to produce analgesia in animals and man gives acupuncture some physiological respectability. In any event, if acupuncture provides effective and safe pain relief then its mechanism of action is of secondary importance. The most fruitful result of research into the neurochemical basis of acupuncture may be the discovery of a means of increasing cerebral release of specific opiate-like peptides and other neurotransmitters. This may be useful for investigating and treating pain and perhaps also some neurological, psychiatric, and neuroendocrine diseases.

1 Research Group of Acupuncture Anaesthesia, Peking. The role of some neurotransmitters of brain in finger-acupuncture analgesia. Sci Sin 1974; $17: 112-30$.

2 Mayer DJ, Price DD, Rafii A. Antagonism of acupuncture analgesia in man by the narcotic antagonist naloxone. Brain Res 1977;121:368-72.

${ }^{3}$ Hosobuchi Y, Rossier J, Bloom FE, Guillemin R. Stimulation of human pariaqueductal gray for pain relief increases immunoreactive $\beta$-endorphin in ventricular fluid. Science $1979 ; 203: 279-81$.

${ }^{4}$ Cheng RS, Pomeranz B. Electroacupuncture analgesia could be mediated by at least two pain-relieving mechanisms: endorphin and nonendorphin systems. Life Sci 1979;25:1957-62.

Fu T-C, Halenda SP, Dewey WL. The effect of hypophysectomy on acupuncture analgesia in the mouse. Brain Res 1980 ;202:33-9.

' Pomeranz B, Cheng R. Suppression of noxious responses in single neurons of cat spinal cord by electroacupuncture and its reversal by the opiate antagonist naloxone. Exp Neurol 1979;64:327-41.

${ }^{7}$ Jieshi C, Zhijin Y, Shupei O. The effect of naloxone on the inhibitory action of electroacupuncture upon cortical potentials evoked by tooth pulp stimulation in rabbits. In: National symposium of acupuncture and moxibustion and acupuncture anaesthesia. Beijing, China: World Books, $1979: 482$.

* Chapman CR, Benedetti C. Analgesia following transcutaneous electrical stimulation and its partial reversal by a narcotic antagonist. Life Sci 1977; $21: 1645-8$.

9 Sjölund BH, Eriksson MB. The influence of naloxone on analgesia produced by peripheral conditioning stimulation. Brain Res 1979;173: 295-301.

1" Chapman CR, Colpitts YM, Benedetti C, Kitaeff R, Gehrig JD. Evoked potential assessment of acupunctural analgesia: attempted reversal with naloxone. Pain 1980;9:183-97.

11 Cheng RS, Pomeranz B. A combined treatment with D-amino acids and electroacupuncture produces a greater analgesia than either treatment alone; naloxone reverses these effects. Pain 1980;8:231-6.

12 Peets JM, Pomeranz B. CXBK mice deficient in opiate receptors show poor electroacupuncture analgesia. Nature $1978 ; 273: 675-6$

${ }^{13}$ Gang Z, Shixiang W, Fangsheng W, et al. Increased levels of endorphins in the cisternal cerebrospinal fluid of rabbits in acupuncture analgesia. In: National symposium of acupuncture and moxibustion and acupuncture anaesthesia. Beijing, China: World Books, 1979:447.

' Sjölund B, Terenius L, Eriksson M. Increased cerebrospinal fluid levels of endorphins after electroacupuncture. Acta Physiol Scand 1977;100: 382-4.

'Xiaoping P, Xianhong L, Suying Y, et al. The relationship between the human CSF levels of endorphins and acupuncture analgesia. In: National symposium of acupuncture and moxibustion and acupuncture anaesthesia. Beijing, China: World Books, 1979:479-80.

${ }^{16}$ Clement-Jones V, Lowry PJ, Rees LH, Besser GM. Development of a specific extracted radioimmunoassay for methionine enkephalin in human plasma and cerebrospinal fluid. 7 Endocrinol 1980;86:231-43.

17 Clement-Jones V, Tomlin S, Rees LH, McLoughlin L, Besser GM, Wen HL. Increased $\beta$-endorphin but not met-enkephalin levels in human cerebrospinal fluid after acupuncture for recurrent pain. Lancet 1980;ii: 946-8, 9.

${ }^{1 *}$ Clement-Jones V, Lowry PJ, McLoughlin L, Besser GM, Rees LH, Wen HL. Acupuncture in heroin addicts: changes in met-enkephalin and 
B-endorphin in blood and cerebrospinal fluid. Lancet 1979;ii:380-2, 3. ${ }^{19}$ Malizia E, Andreucci G, Paoluci D, Crescenzi F, Fabbri A, Fraioli F Electroacupuncture and peripheral $\beta$-endorphin and ACTH levels. Lancet 1979 ;ii:535-6.

20 Abbate D, Santamaria A, Brambilla A, Panerai AE, Di Giulio AM. $\beta$-Endorphin and electroacupuncture. Lancet 1980;ii:1309.

21 Wen HL, Ng YH, Ho WKK, et al. Acupuncture in narcotic withdrawal: a preliminary report on biochemical changes in the blood and urine of heroin addicts. Bull Narc 1978;30,2:31-9.

22 Stubbs WA, Delitala G, Jones A, et al. Hormonal and metabolic responses to an enkephalin analogue in normal man. Lancet 1978;ii:1225-7.

${ }^{23}$ Gaillard RC, Grossman A, Smith R, Rees LH, Besser GM. The effects of a met-enkephalin analogue on ACTH, $\beta$-LPH, $\beta$-endorphin and metenkephalin in patients with adrenocortical disease. Clin Endocrinol 1981 ; 14:471-8.

${ }^{24}$ Pomeranz B, Cheng R, Law P. Acupuncture reduces electrophysiological and behavioural responses to noxious stimuli: pituitary is implicated. Exp Neurol 1977;54:172-8.

${ }^{25}$ Jeffcoate WJ, McLoughlin L, Hope J, et al. $\beta$-Endorphin in human cerebrospinal fluid. Lancet 1978;ii:119-21.

26 Chi-Sheng H, Pao-Ho C, Chen-Chy L, Lian-Hua L, Tsung-Hsien Y, Min-Feng J. The role of central 5-hydroxytryptamine in acupuncture analgesia. Sci Sin 1979;22:91-104.

27 Ching-Cheng Y, Ta-Hsien L, Shih-Hsiang W, Kang T. A study on the release of $3 \mathrm{H}-5$-hydroxytryptamine from brain during acupuncture and morphine analgesia. Sci Sin 1977;20:113-24.

28 McLennan H, Gilfillan K, Heap Y. Some pharmacological observations on the analgesia induced by acupuncture in rabbits. Pain $1977 ; 3: 229-38$.

${ }^{29}$ Jisheng H, Minfeng Re, Jian T, Shaoguang F, Jinmin X, Xinmin G. The role of central catecholamine in acupuncture analgesia. Chin Med 1979 ; 92:793-800.

${ }^{30}$ Basbaum AI, Fields HL. Endogenous pain control mechanisms: review and hypothesis. Ann Neurol 1978;iv:451-62.

${ }^{31}$ Levine JD, Gordon NC, Fields HL. The mechanism of placebo analgesia Lancet 1978 ;ii :654-7.

\section{Pathological fractures due to bone metastases}

The observation that cancerous tumours may spread to bone and destroy it was first made by clinicians in the late eighteenth and early nineteenth centuries. ${ }^{1}$ With increased understanding of the "carious" condition of the bone they became aware of the need to treat this secondary problem in an active way despite the patient's poor overall prognosis.

The surgeon today has several techniques for dealing with bone metastases, as well as modern anaesthesia and chemotherapy to help him in his task. Indeed, the problem is often technically simple; but it raises profound ethical problems about the welfare of a patient who has only a short time to live. Surgery, however, may produce the considerable benefits of pain relief and increased mobility, and should not be withheld from any patient if even brief improvement is likely.

Skeletal scintigraphy ${ }^{2}$ is now established for early diagnosis of skeletal metastases. This poses the problem of whether prophylactic internal fixation should be carried out, as not all metastases in bone are likely to cause a fracture. But prophylactic fixation prevents stress and pain, and is technically much easier than fixation of a comminuted displaced fracture in soft bone. In long bones increasing pain and destruction of more than half the cortex as seen on an $x$-ray film are indications for prophylactic internal fixation ${ }^{3}$; local irradiation of the lesion is a further indication, since this increases the risk of fracture. ${ }^{4}$ In patients with advanced disease any risk of local or general spread of the tumour is outweighed by the benefits of the procedure. ${ }^{3-5}$

Most pathological fractures of the long bones will be treated by internal fixation with a plate or nail plate or with an intra- medullary rod. In all cases a biopsy specimen should be taken at the time of operation to confirm the nature of the lesion and help in planning radiotherapy or chemotherapy after operation. Fractures of the femoral neck are best treated by replacement arthroplasty. ${ }^{4}$ When a large part of the upper femur is destroyed special femoral prostheses designed for extensive replacement of bone may be required. Problems may arise with large lesions that destroy much bone, and here metal plates may be combined with high-density polyethylene plates ${ }^{6}$ or nylon plates and straps. ${ }^{7}$

During the last 10 years methyl methacrylate cement has been used to supplement internal fixation, the material being used to replace the tumour and restore the mechanical continuity of the bone. By moulding methyl methacrylate round a metal device the shape of the bone can be restored. ${ }^{8}$ Yablon and Paul $^{9}$ reported the use of methyl methacrylate in 73 patients with 81 pathological fractures. They concluded that although methyl methacrylate probably had an adverse effect on fracture healing fixation was adequate, there being no failure of fixation in their series. Twelve of their patients had survived over five years, and only four failed to regain function in the limb that had been operated on. Harrington $e t$ al ${ }^{10}$ achieved similar success in a smaller series of patients. More recently Harrington $^{11}$ has used methyl methacrylate for replacement and stabilisation of vertebral bodies in pathological fracturedislocations of the spine. In a series of 14 patients followed up for 13-45 months there was only one failure of fixation. Of $\vec{\epsilon}$ 12 patients with major neural lesions before operation, nine $\$$ had complete neurological recovery after surgery. Two others were improved and one was unchanged. None deteriorated neurologically.

Pathological fractures occur in under $1^{\prime \prime}$, of patients with advanced carcinoma. ${ }^{12}$ When a fracture does occur, however, it inflicts a dismal burden on a patient, often at the end of life. As the number of elderly people in the population increases the incidence of these fractures is likely to rise. Improved surgical, radiological, and chemotherapeutic techniques have given patients with advanced cancer a longer life span. The resources for dealing with disabling secondary disease will need to be correspondingly increased if these patients are to live the end of their lives in dignity and without pain.

Onuigbo W'IB. Recognition and treatment of pathologic fractures in the nineteenth century. Surgery 1975;77:553-6.

- Galasko CSB. The pathological basis for skeletal scintigraphy. $\mathcal{F}$ Bone foint Surg (Br) 1975;57B:353-9.

${ }^{3}$ Fidler MW, Stollard G. The management of secondary neoplastic deposits in long bones by prophylactic internal fixation. Archivum Chirurgicum Neerlandicum 1977;29:177-85.

- Galasko CSB. Pathological fracture secondary to metastatic cancer. $\mathcal{f} R$ Coll Surg Edinb 1974;19:351-62.

'Heisterberg I, Johansen TS. Treatment of pathological fractures. Acta Orthop Siand 1979;50:787-90.

Gallannaugh SC. High density polyethylene plate for fracture fixation in the elderly. Br Med f 1975;iv:560.

$\checkmark$ Partridge A. Nylon plates and straps for internal fixation of osteoporotic bone. Lancet 1977; ;:808.

'Ray AK, Romine JS, Pankovich AM. Stabilisation of pathologic fractures with acrylic cement. Clin ()rthop 1974;101:182-5.

9 Yablon IG, Paul GR. The augmentive use of methyl methacrylate in the management of pathologic fractures. Surg Gynciol Obstet 1967;143 177-83.

1" Harrington KD, Johnston JO, Turner RH, Green DL. The use of methylmethacrylate as an adjunct in the internal fixation of malignant neoplastic fractures. F Bone foint Surg $(A m)$ 1972;54A:1665-76.

1 Harrington KD. The use of methylmethacrylate for vertebral-body replacement and anterior stabilisation of pathological fracture-dislocations of the spine due to metastatic malignant disease. 7 Bone foint Surg (Am) 1981 ;63A :36-46.

- Galasko CSB. Skeletal metastases and mammary cancer. Ann R Coll Surg Engl $1972 ; 50: 3-28$. 